\title{
COASTLINE CHANGES DETECTION USING SENTINEL-1 SATELLITE IMAGERY IN SURABAYA, EAST JAVA, INDONESIA
}

\author{
Filsa Bioresita ${ }^{1}$, Noorlaila Hayati ${ }^{1}$ \\ ${ }^{1}$ Geomatics Engineering, Faculty of Civil Engineering and Planning, Institut Teknologi Sepuluh Nopember, \\ Surabaya 60111 \\ Email: filsa.bioresita@gmail.com
}

\begin{abstract}
One of the most important linear features on the earth's surface is coastline. Coastal zone and its environmental management require the information about coastlines and their changes, which display a dynamic nature. The coastal area of Surabaya has the most dominant sedimentation. This is due to the presence of several large rivers flow in the area, which brings sediment to the estuary. In addition, the development of Suramadu bridge that across Madura strait, connecting Java and Madura islands, has opened an opportunity for the areas around the Suramadu Bridge to be the region of industry activities in East Java. It can give sizeable influence for the physical change that happens around the Suramadu Bridge in particular south coastal area of Bangkalan, Madura and north coastal area of Surabaya as the change of coastline and the wide change of land area caused by natural factor or human activities. Sentinel-1 is one of a Sentinels technology which is a polar-orbiting, all-weather, day-and-night radar imaging mission for land and ocean services at C-band. This image is not limited by weather conditions or darkness and effective to separate land and water objects. The availability of Sentinel-1 images that have high spatial resolution and high temporal frequency, facilitate the monitoring of coastline changes. The aim of this paper was to analyze the ability of Sentinel-1 imagery to delineate coastline and their changes. Detection of the coastline changes can be done by choosing the best extracted parameter from Sentinel-1 and by setting threshold for land and water separations. Furthermore, the results of processed images were overlayed based on multi temporal. From this research, it could be expected that sigma-nought from VH polarization is the best parameter for the land and water separations which threshold determination is according to the distribution values of sigma-nought. However, there are no big differences of coastline changes viewed by changes detection in some Sentinel-1 images since the monitoring was carried out every month.
\end{abstract}

Keywords: Coastline, Sentinel-1 images, Extracted parameter, Threshold, Overlay

\section{INTRODUCTION}

\section{Background}

A coast is a unique environment where land meets the sea or ocean. In this area, atmosphere, hydrosphere, and lithosphere contact each other. Coastline is a line that forms the boundary between land and water body. It is one of the most important linear features on the earth's surface, which has a dynamic nature (Alesheikh, et.al., 2007). Knowledge of coastline is the basis for measuring and characterizing land and water resources (Liu and Jezek, 2004). Coastal line area has changed due to either natural physics of earth or human activities. Coastal zone monitoring is an important task in sustainable development and environmental protection.
Surabaya - Madura Coastline has an interesting characteristic because of not only the affection of Lapindo Mud flowing to the sea which brings sedimentation but also the side effect of development's Suramadu Bridge. Coastline of Surabaya-Madura also has an important role for shipping line on Eastern Indonesia due to Surabaya as an industrial city. Therefore, coastline area in Surabaya has to be monitored to know better the changing of physical environment.

There are many methods to monitor coastline changes. However, a few methods such as ground surveying spend many cost and effort. The best method is using remote sensing technology which the environment is measured using satellite. Optical images of remote sensing provide a simple way to interpret and easily obtainable. Unfortunately, those images sometimes have 
issues with weather condition. Nowadays, radar remote sensing has high expectation to resolve this problem because it works for day, night and all weather time. In this research, Sentinel-1 CSAR (Synthetic Aperture Radar), the new one of radar remote sensing satellite provided by European Space Agency (ESA), is used.

Sentinel- 1 is one of a Sentinels technology which is a polar-orbiting, all-weather, day-and-night radar imaging mission for land and ocean services at C-band, a 5.546 wavelength. This image is limited neither by weather conditions nor darkness and effective to separate land and water objects. The availability of Sentinel-1 images in which both high spatial resolution and high temporal frequency facilitates the monitoring of coastline changes.

The most important rule to detect coastline area is doing separation of land class and water class. Various methods for coastline extraction from remote sensing imagery have been developed. Coastline can be extracted from a single band image with thresholding analysis. Hence, the method is expected to accurately evaluate two classes of land and water. However, this result of segmentation is also depending on the parameter of satellite systems such as wavelength, spatial resolution, incidence angle, and polarization (Matgen et al, 2011), the quality of base map used as the reference point of histogram classification, and the algorithm processed on this research.

There are two general information of synthetic aperture radar, amplitude and phase. Phase information will not be used in this research because the amplitude is sufficient to provide the required information. Therefore the imagery type used is Sentinel-1 GRD which only contains amplitude information. In this research, that thresholding analysis is applied to Sentinel-1 GRD imagery.

Many previous researches have been introduced to monitor floods using histogram thresholding (Schumann et al, 2010) and combination of both radiometric thresholding and region growing (Matgen et al, 2011). They showed that SAR images have high promise for floods monitoring. According to that case, this research attempted using the technology to monitor coastline provided by multi-temporal SAR Sentinel-1 images. The aim of this paper was to analyze the ability of Sentinel-1 imagery to delineate coastline and their changes. A few months Sentinel-1 imageries accession dates were used in SurabayaMadura location to detect coastline changes monthly. Furthermore, the general overlay method based on geographic location would be applied to know precisely the changes of coastline according to the threshold segmentation from each SAR imagery.

\section{RESEARCH METHODOLOGY}

\section{Data}

Six images of Sentinel-1 IW GRDH data acquired since November 2014 until Avril 2015 were obtained from European Space Agency (ESA) Sentinels Scientific Data Hub. The obtained Sentinel data were re-projected to WGS-84 coordinate system. Then for the final image, all results will be re-projected again to UTM zone 49 South projection. Coastline map from Geospatial Information Agency of Indonesia with scale 1:250.000 was used as reference of sample mask. For comparison, the coastline data from previous research were used in this study.

Table 1. The Sentinel-1 IW GRDH data used.

\begin{tabular}{ccc}
\hline No & Image Acquisition & \multicolumn{1}{c}{ Polarization } \\
\hline 1 & 10 November 2014 & $\mathrm{VV}, \mathrm{VH}$ (double polarization) \\
2 & 28 December 2014 & $\mathrm{VV}, \mathrm{VH}$ (double polarization) \\
3 & 21 January 2015 & $\mathrm{VV}, \mathrm{VH}$ (double polarization) \\
4 & 26 February 2015 & $\mathrm{VV}, \mathrm{VH}$ (double polarization) \\
5 & 22 March 2015 & $\mathrm{VV}, \mathrm{VH}$ (double polarization) \\
6 & 15 April 2015 & $\mathrm{VV}, \mathrm{VH}$ (double polarization) \\
\hline
\end{tabular}

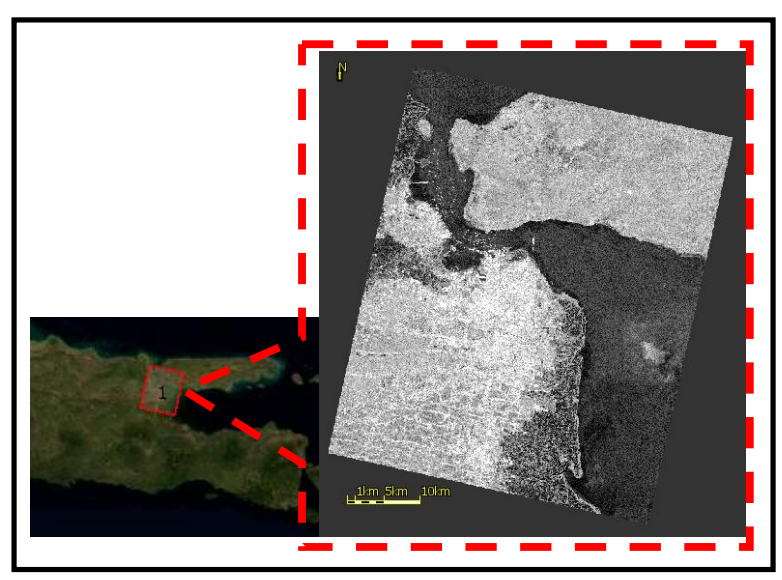

Figure 1. Study area. 


\section{Methods}

Figure 2 shows the overall methods adopted in this study to detect the coastline changes.

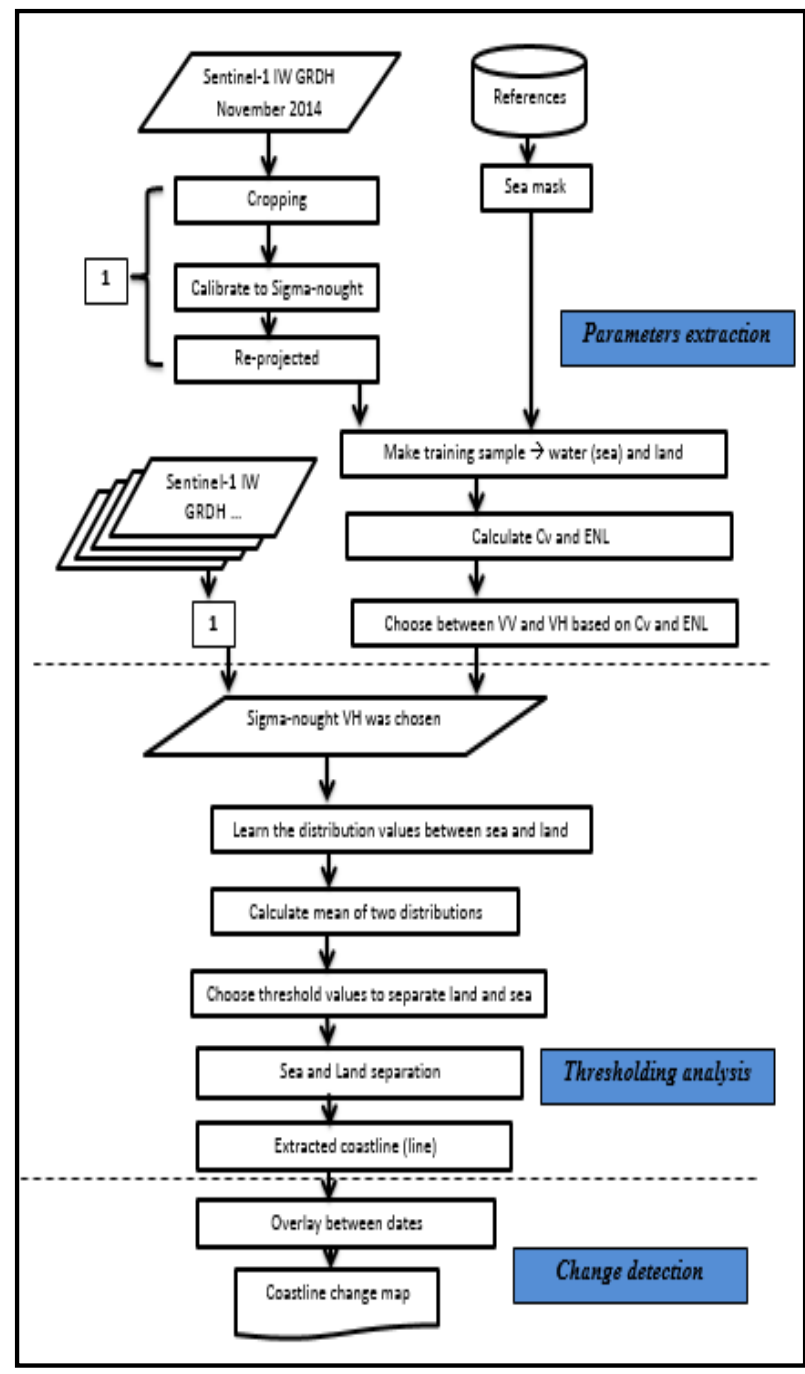

Figure 2. Flowchart showing the overall methods adopted in this study.

Sentinel-1 GRD IW dual polarization (VV+VH) 10 November 2014 was used to extract its parameters. Sigma-nought parameter was chosen because it has the best power (energy) returned to the antenna from the ground plane and is thus in the realm of ground range. That condition is very appropriate with the type of Sentinel-1 data used in here (Ground Range Detected (GRD) products). Besides, the sigma-nought was calibrated product which is better than noncalibrated products (amplitude and intensity).

The land and sea area from image satellite must be separated to be able to map coastline. Separation can be done based on the distribution of backscattering values of sigma-nought images between land and water classes. Thus, the sample mask of sea and land regions were built from reference map to learn about distribution values,. The purpose of this step was to determine the best sigma-nought image (between $\mathrm{VV}$ and $\mathrm{VH}$ polarization) to be used in this research. $\mathrm{CV}$ and ENL values of each classes were calculated to evaluate the quality of polarimetric signal. In other words, the smaller $\mathrm{C} v$ values and the bigger ENL values, the better quality of polarimetric signal.

In order to determine thresholds for each of sigma-nought, the distribution values between sea and land were learned. Mean of each classes from all sigma-nought images were calculated. Furthermore, the threshold value of each images were determined based on mean value of sea class distribution and mean value of land class distribution divided by two. Afterward, land and sea were separated with masking process. The result images were filtered with median method to produce the clearer images, reduce the noise, and show obvious delineation between the land and sea region.

The results of land and sea separation in November 2014 until April 2015 were overlaid to be able to see the difference of coastline between the couple of dates. The length of each coastline from different date were calculated and compared. The performance of Sentinel-1 IW GRDH to map coastline was analyzed and compared with the other images data from previous research (Handayani, 2014).

\section{RESULTS AND DISCUSSION}

\section{Evaluate The Quality of Polarimetric Signal}

Sentinel-1 IW GRDH type has two images product in $\mathrm{VV}$ and $\mathrm{VH}$ polarization. $\mathrm{CV}$ and $\mathrm{ENL}$ values of each classes were calculated to evaluate the quality of polarimetric signal to determine the best image to be used in this research.

Table 2. Cv and ENL values of sigma 10/11/2014.

\begin{tabular}{cccc}
\hline Parameters & Class & Cv & ENL \\
\hline Sigma VV db & Land & 0.8279 & 1.4591 \\
$10 / 11 / 2014$ & Sea & 0.3624 & 7.6153 \\
Sigma VH db & Land & 0.4746 & 4.4388 \\
$10 / 11 / 2014$ & Sea & 0.2375 & 17.7240 \\
\hline
\end{tabular}


From Table 2, it can be seen that VH polarization has better quality, because it has smaller values of $\mathrm{CV}$ and bigger values of ENL than VV polarization. Therefore in this research sigma-nought $\mathrm{VH}$ polarization would be used.

\section{The Separation of Land and Sea Area}

Land and sea separation from sigma-nought image of Sentinel-1 IW GRDH could be done with density slicing. In this research, threshold value would be used as a point which slice the sigmanought values into two classes or make binary image. To be able to determine threshold values of each sigma-nought images from each dates, thresholding analysis was done.

Figure 3 shows about distribution values of sea and land classes from sigma-nought $\mathrm{VH}$ $10 / 11 / 2014$ and $28 / 12 / 2014$. From that graphics, it can be seen that there is an intersection area between sea and land distribution. Threshold value would be determined in that area by applying the equation (1). Table 3 indicates mean values of each sigma-nought images.

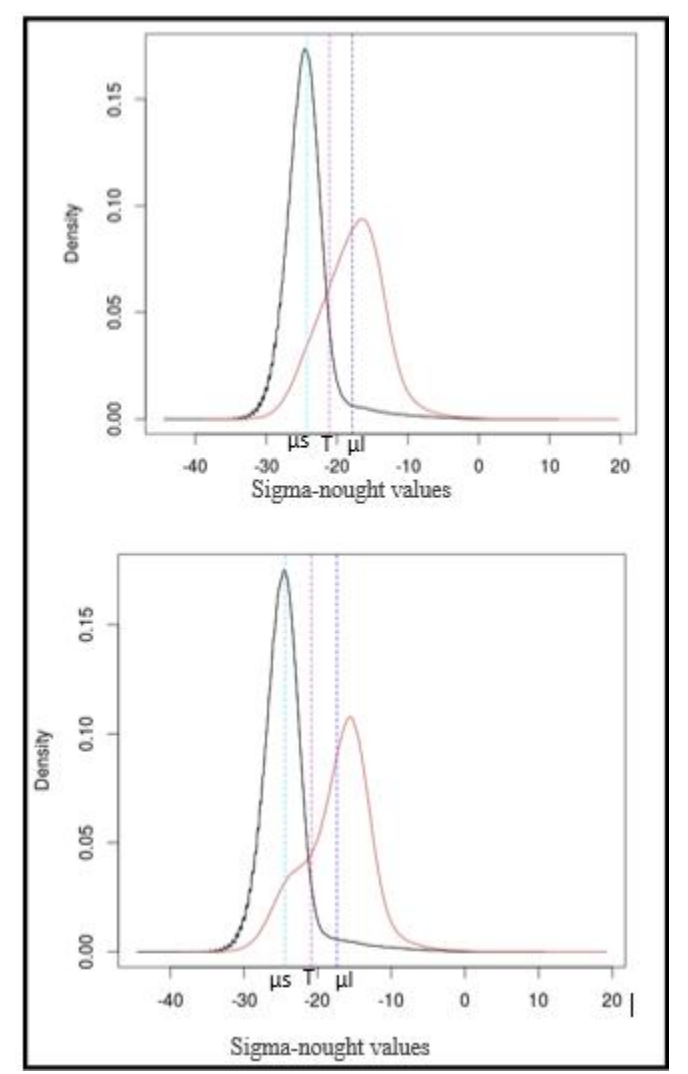

Figure 3. Sigma-nought VH 10/11/2014 (up) and 28/12/2014 (down) distribution values.

$$
\begin{aligned}
& T=\frac{\mu s+\mu l}{2} \\
& T=\text { Threshold value } \\
& \mu s=\text { Mean value of sea class distribution } \\
& \mu l=\text { Mean value of land class distribution }
\end{aligned}
$$

Table 3. Mean and threshold values of each sigmanought images.

\begin{tabular}{ccccc}
\hline No & Image Acquisition & $\boldsymbol{\mu S}$ & $\boldsymbol{\mu l}$ & $\mathbf{T}$ \\
\hline 1 & 10 November 2014 & -24.266 & -17.855 & -21.060 \\
2 & 28 December 2014 & -24.375 & -17.377 & -20.876 \\
3 & 21 January 2015 & -24.592 & -17.105 & -20.848 \\
4 & 26 February 2015 & -24.540 & -16.907 & -20.724 \\
5 & 22 March 2015 & -23.584 & -16.086 & -19.835 \\
6 & 15 April 2015 & -23.355 & -16.877 & -19.616 \\
\hline
\end{tabular}

The result of density slicing was a binary image with two classes, land and sea, as shown in Figure 4 . It can be seen that there was many noise in the result image. Therefore, median filter with $3 \times 3$ kernel size was applied to all result images. That filtering made the separation of sea and land class more obvious. Then it would be easier to extract coastline from those images result.

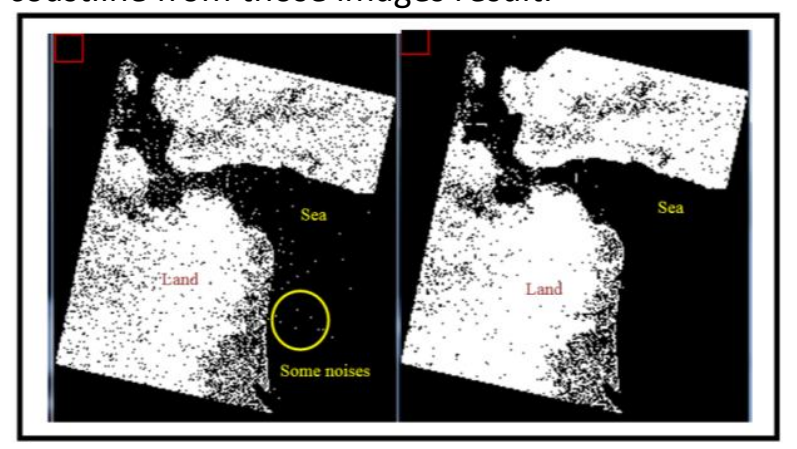

Figure 4. Binary images of 10/11/2014 before (left) and after filtering (right).

\section{Coastline Extraction from Sentinel-1 Image}

Coastline mapping from sigma-nought of Sentinel1 IW GRDH image provides a detail shape. The result mapped out not only the bay or cape, but also the ports along the coast. This is very usefull to monitor port change from year to year. Fig. 5 shows the coastline map which captures the details of the port form. Compared to the previous research which used Landsat 8 data, Sentinel-1 data have more ability to capture the details of coastal areas. From this result, it can be said that the ability of Sentinel-1 data for coastline mapping are very high. Sentinel-1 data will be very useful for coastline monitoring in the future when there are more annually data. 


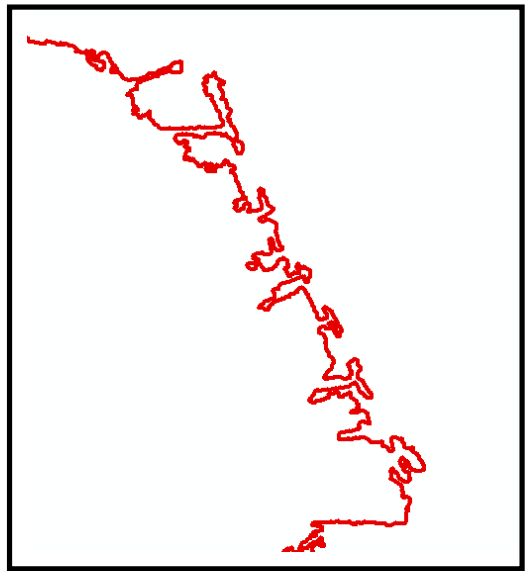

Figure. 5 Port form details captured from Sentinel-1 image.

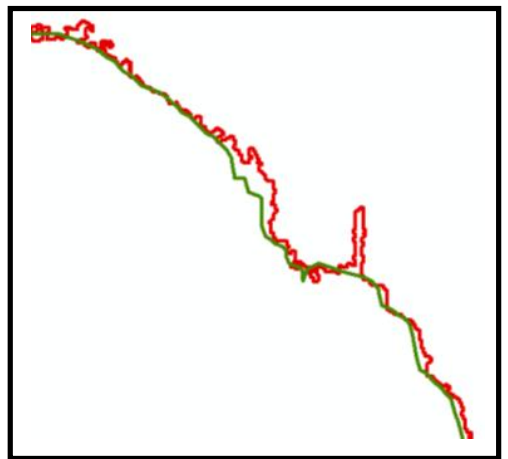

Figure 6. Coastline extraction from Sentinel-1 data (red) and Landsat 8 data (green).

However, the separation of land and sea from Sentinel-1 data was also making some separation of surface waters or humid areas and land as shown in Fig. 7, because the surface waters or humid areas and sea have almost same backscattering values. Then when density slicing performed, surface waters became the same class with sea. But for this study, this case did not influence coastline extraction because the important one is the boundary between land and sea.

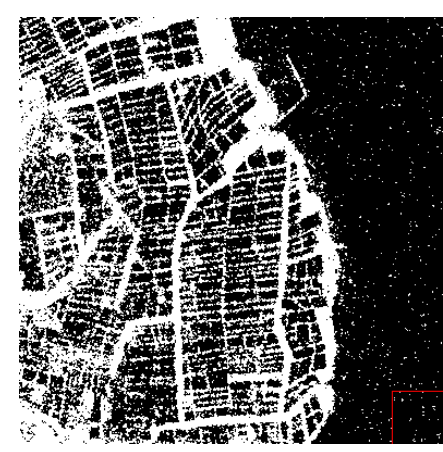

Fig. 7.Some surface waters or humid areas separated to land.

\section{Coastline Changes Detection}

Generally, coastline changes have been monitored annually. However, in this research, the focus of study is to know the ability of Sentinel image data, which have high temporal acquisition, for monitoring of coastline monthly. The results show that there are no major changes occur between November 2014 until April 2015. Table 4 shows about the coastline length calculation in that dates.

Table 4. Coastline length calculation.

\begin{tabular}{cccc}
\hline No & Image Acquisition & $\begin{array}{c}\text { Surabaya and } \\
\text { Surrounding } \\
\text { Areas Coastline } \\
\text { Length }\end{array}$ & $\begin{array}{c}\text { Madura } \\
\text { Coastline } \\
\text { Length }\end{array}$ \\
\hline 1 & 10 November 2014 & $223144.074 \mathrm{~m}$ & $126507.276 \mathrm{~m}$ \\
2 & 28 December 2014 & $190901.626 \mathrm{~m}$ & $108137.662 \mathrm{~m}$ \\
3 & 21 January 2015 & $196246.076 \mathrm{~m}$ & $130942.814 \mathrm{~m}$ \\
4 & 26 February 2015 & $214871.083 \mathrm{~m}$ & $111913.468 \mathrm{~m}$ \\
5 & 22 March 2015 & $196592.406 \mathrm{~m}$ & $116201.095 \mathrm{~m}$ \\
6 & 15 April 2015 & $182850.888 \mathrm{~m}$ & $114857.099 \mathrm{~m}$ \\
\hline
\end{tabular}

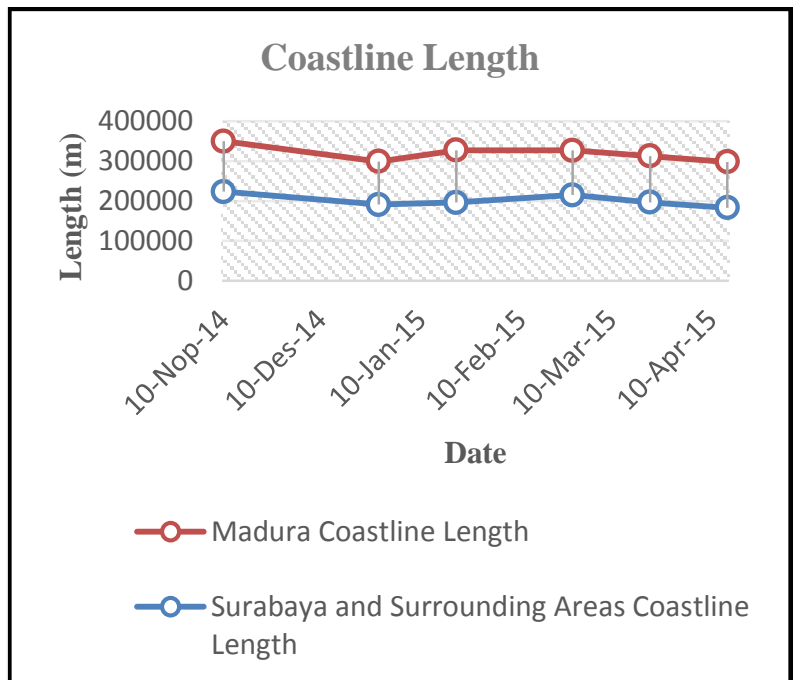

Figure 8. Diagram of coastline length changes.

From Figure 8 , the diagram indicates the same trend of coastline length changes in Surabaya and Madura side. From November to December 2014, coastline length tends to decrease. Nevertheless, it increased on January 2015 and February 2015. But it decreased again in March until April 2015. The calculation was carried out in the coastline inside of area shown in Figure 9.

In this study, land areas were calculated to be able to see their changes between November 2014 to April 2015. The results as shown in Table 5 and Figure 10 indicate no great difference through that dates. It occurs for both of them, 
Surabaya and surrounding areas and Madura areas. In Madura side some areas around Suramadu Bridge have changes. It is seen from January 2015 image that they extend. In Surabaya side, some changes areas are seen from February 2015 images around Suramadu Bridge. Some dynamic changes were also occurs in the north coastline of Surabaya, precisely around Tanjung Perak Harbour areas. The coastline changes map and land areas changes map can be seen in the appendix.

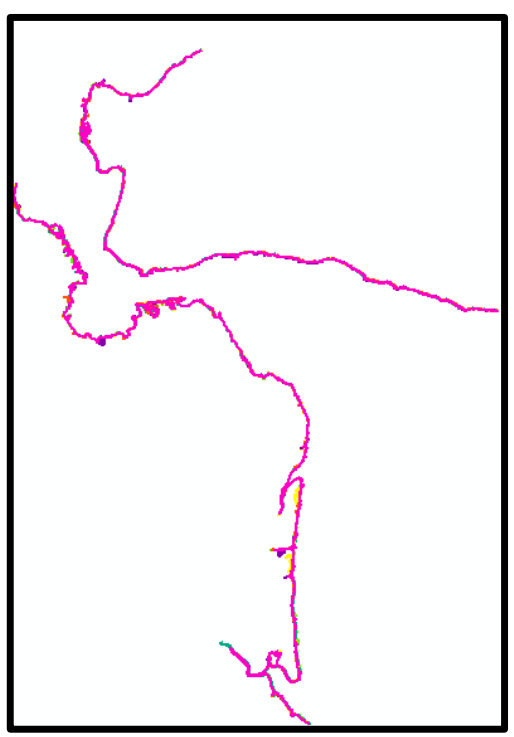

Figure 9. Coastline area.

Table 5.Areas calculation.

\begin{tabular}{cccc}
\hline No & Image Acquisition & $\begin{array}{c}\text { Surabaya and } \\
\text { Surrounding } \\
\text { Areas (ha) }\end{array}$ & $\begin{array}{c}\text { Madura } \\
\text { Areas (ha) }\end{array}$ \\
\hline 1 & 10 November 2014 & 96396.198 & 55725.692 \\
2 & 28 December 2014 & 96463.389 & 55626.827 \\
3 & 21 January 2015 & 96253.982 & 55769.655 \\
4 & 26 February 2015 & 96958.515 & 55734.806 \\
5 & 22 March 2015 & 96890.029 & 55760.239 \\
6 & 15 April 2015 & 96051.545 & 55742.067 \\
\hline
\end{tabular}

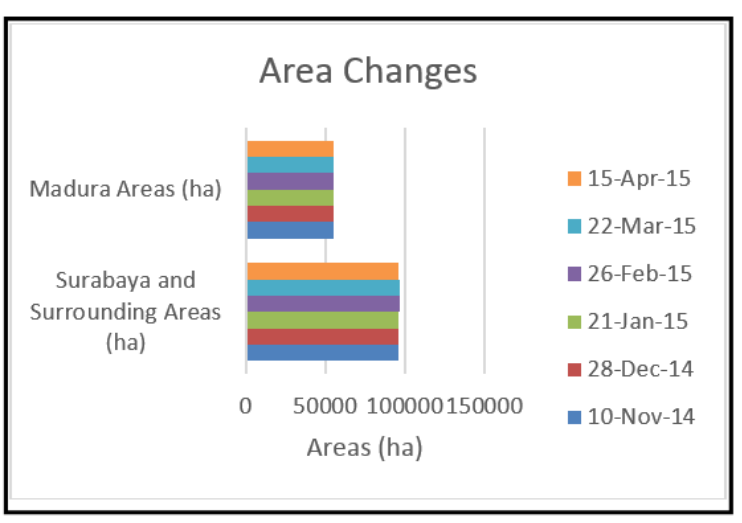

Figure 10. Diagram of areas changes.
Since there is no major difference of coastline changes in November 2014-April 2015 period, comparison was made based on the previous research which carry out coastline of 1994, 2003, 2009, 2012, and 2013. Furthermore, coastline from December 2014 and March 2015 images of Sentinel-1 data were chosen as 2014 and 2015 coastline. Figure 11 points out the coastline changes between that time periods.

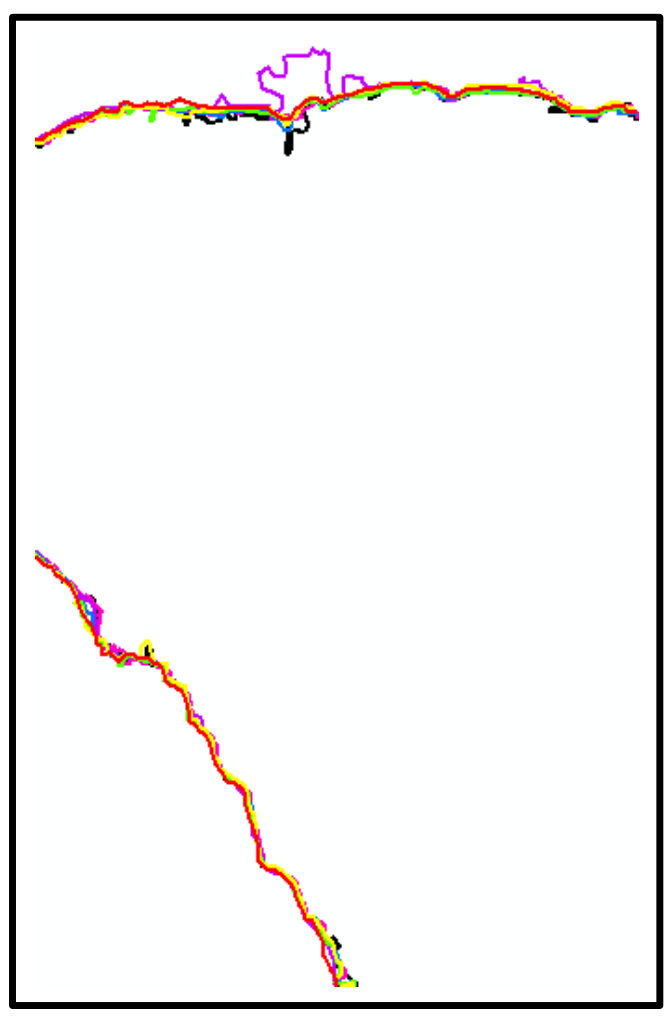

Figure 11. Coastlines comparison from 1994 to 2015.

For Surabaya areas, some major changes occurred in TambakWedi areas which were coastal areas between north coast zone of Surabaya and Suramadu Bridge. It also occurred around Suramadu Bridge and Kenjeran areas. It was happened probably because there are the side effect of Sidoarjo Mud flowing to coastal area and also the construction of Suramadu Bridge which has made another development such as urban areas in coastal areas of Surabaya. In the other side, Madura was also experiencing siginificantly major changes around Suramadu Bridge due to the development of edge Suramadu Bridge as a new trading and market area. Figure 12 show about coastline length changes since 1994 to 2015. 


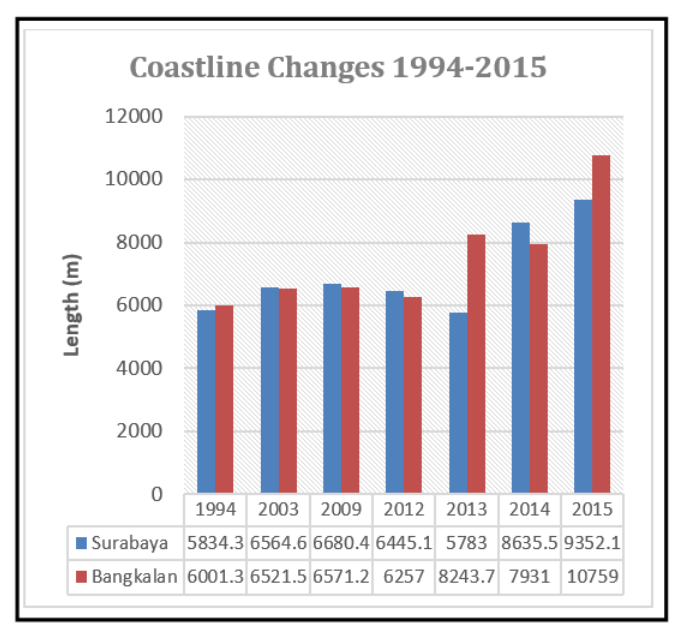

Figure 12.Coastlines changes from 1994 to 2015.

\section{CONCLUSIONS}

Generally, there are no major changes occurred between November 2014 until April 2015 viewed by a couple processed images of Sentinel-1 since the temporal of accused images was not quiet long but some dynamic changes has occurred in the north coastline of Surabaya, precisely around Tanjung Perak Harbour areas. Moreover, we also compared these microwave images to optical images to know better the coastline change in recent years. We concluded that the change of coastline at Madura region was more significant than at Surabaya region.

Based on the distribution values of sea and land classes from sigma-nought VH 10/11/2014 and $28 / 12 / 2014$, it can be seen that there is an intersection area between sea and land distribution. However, the separation of land and sea from Sentinel-1 data was also making some separation of surface waters or humid areas and land due to mostly similar backscattering values. Fortunately, this case did not influence coastline extraction because the important one is the boundary between land and sea.

According to evaluation, $\mathrm{VH}$ polarization has better quality of polarimetric signal than VV. Threshold value between land and sea separation has been determined by the average of mean sigma-nought distribution values in each class. We realized that this method still has a drawback which some distribution values could be put in the wrong classification due to inaccurate threshold determination (the border bias). Thus, it is better applying another advance method such as Split
Based Approach (SBA) to determine the local threshold instead of global threshold.

\section{ACKNOWLEDGEMENT}

The authors would like to thank four parties who provide data. Firstly, we thank to European Space Agency for the provision of Sentinel-1 IW GRDH data. The second one, it is for Handayani et.al., 2014 to provide the coastline result of 2013 as a previous research. Third is the previous research of Rohmah, M. N., 2013 for the coastline result from 1994 to 2012. Lastly, we also thank to the Ina Geo Portal website of Geospatial Information Agency, Indonesia for the references map used to the sample mask.

\section{REFERENCES}

Alesheikh, A. A., Ghorbanali, A., and Nouri, N., "Coastline Change Detection Using Remote Sensing," Int. J. Environ. Sci. Tech., vol. 4, no. 1, pp. 61-66, 2007.

Handayani, H. H., Yuwono, Khomsin, and Taufik, M., "Study for Comparative Analysis of Changes in Shore Line Using Multi Stage Satellite Images (Case Study: Gresik and Bangkalan, Indonesia),"FIG Congress, Kuala Lumpur, Malaysia, 2014.

Liu, H. and Jezek, K. C., "A Complete HighResolution Coastline of Antarctica Extracted from OrthorectifiedRadarsat SAR Imagery," Photogrammetric Engineering \& Remote Sensing, vol. 70, no. 5, pp. 605-616, May 2004.

Lopez-Caloca, A., Tapia-Silva, F.O., and EscalanteRamirez, B., "Lake Chapala change detection using time series," Remote Sens. Agric. Ecosyst. Hydrol., vol. 7104, pp. 1-11, 2008.

Matgen, P., Hostache, R., Schumann, G., Pfister, L., Hoffmann, L., and Savenije, H.H.G., "Towards an Automated SAR-based Flood Monitoring System: Lessons Learned from Two Case Studies," Physics and Chemistry of the Earth, vol. 36, pp. 241-252, 2011.

Rohmah, M. N., "Study of Coastline Change in The Surabaya and Madura Coastal Area after The Development of Suramadu BridgeUsing Multi Temporal Satellite Image," Undergraduate Thesis, SepuluhNopember Institute of Technology, Indonesia, 2013. 


\section{APPENDIX}
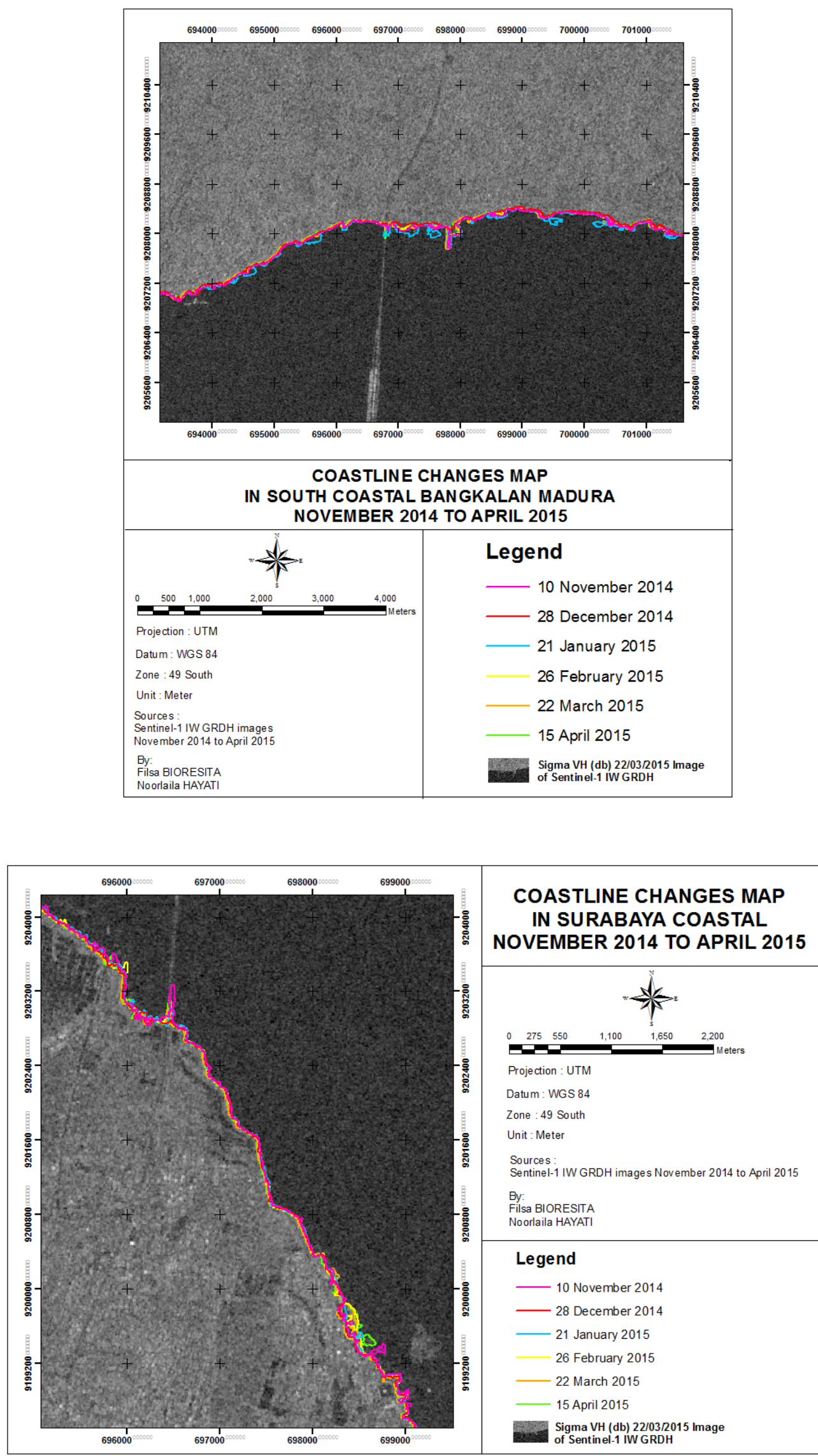

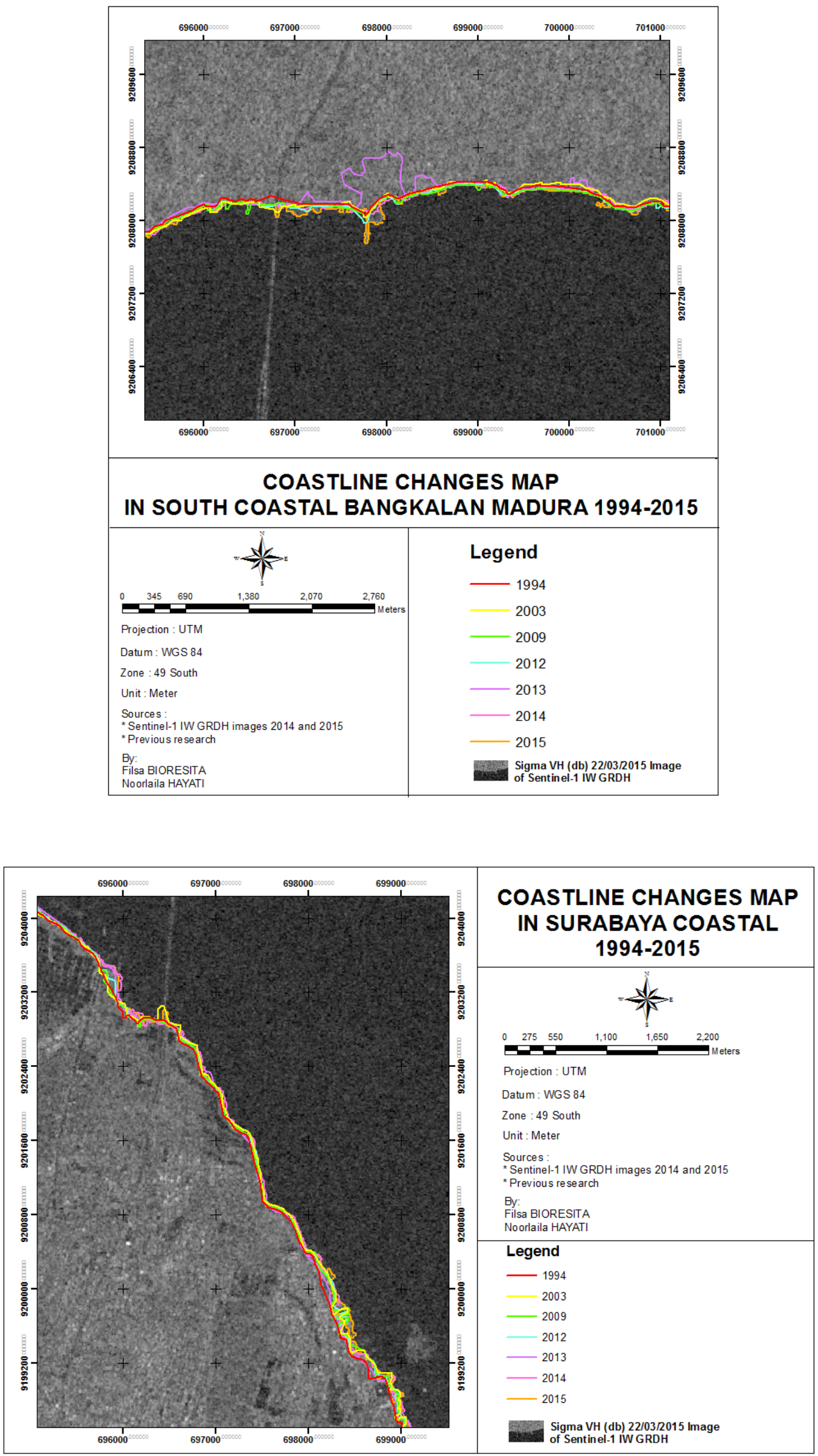